\title{
Turismo en automóvil en Argentina (1920-1950)
}

Melina Piglia*

En 1900 circulaban poco más de cien automotores en la Argentina y su número siguió creciendo rápidamente: en 1910 había llegado a 4.800 y a más de 48 mil diez años después. Exótico juguete de lujo en los primeros años del siglo Xx, tras la Primera Guerra Mundial el automóvil se difundió rápidamente en la Argentina entre la élite agroganadera primero y entre sectores medios y medios altos, después. Los automóviles fueron haciéndose más versátiles, confiables y económicamente accesibles y, hacia los años de 1920, se habían afirmaron en la Argentina como medios de transporte. El automóvil fue mucho más: se convirtió en un modo importante de marcar y exhibir el estatus (adinerado, sofisticado, moderno) de su propietario, en un objeto de deseo y en un significante cultural central. El automóvil era libertad, movimiento, velocidad que comprimía el tiempo y achicaba las distancias, era un símbolo de la modernidad.

La Argentina llegó a ser en la entreguerra, el país latinoamericano con más automóviles y osciló entre el cuarto y séptimo lugar mundial ${ }^{1}$. Sobre todo, tenía un número muy elevado de automóviles en relación con su población y en relación con su escaso kilometraje de caminos permanentes (Tablas 1 y 2).

* Universidade Nacional de Mar del Plata - UnMdp (Argentina).

1. En Latinoamérica circulaban en total en 1927 poco más de 600 mil automóviles, 200 mil de ellos en la poco poblada Argentina, 100 mil en Brasil (que tenía el triple de población y superficie que la Argentina) y poco menos de 20 mil en Chile. 
TABLA 1

Cantidad de Habitantes por Automóvil

\begin{tabular}{rcccc}
\hline AÑO & ESTADOS UNIDOS & FRANCIA & GRAN BRETAÑA & ARGENTINA \\
\hline 1907 & 608 & 981 & (sin dados) & 2.000 \\
1913 & 77 & 318 & 165 & 640 \\
1920 & 13 & 164 & 58 & 160 \\
1927 & 6 & 43 & 39 & 49 \\
\hline
\end{tabular}

Fuentes: Margalit (2016), McShane (1995) e “Estadística mundial de automóviles” (1923, 1927).

TABLA 2

Proporción de Caminos/Automotores y de $\mathrm{km}^{2}$ de Territorio Nacional/km de Caminos en el Mundo (1926)

\begin{tabular}{|c|c|c|}
\hline PAÍS & $\begin{array}{c}\text { NÚMERO DE AUTOMOTORES } \\
\text { POR CADA KILÓMETRO DE CAMINO }\end{array}$ & $\begin{array}{l}\text { KMㄹㄹ DE TERRITORIO POR CADA } \\
\text { KILÓMETRO DE CAMINO }\end{array}$ \\
\hline Estados Unidos & 4,6 & 1,6 \\
\hline Gran Bretaña & 3,6 & 0,81 \\
\hline Australia & 2,2 & 45 \\
\hline Argentina & 7,5 & 93,24 \\
\hline Brasil & 2,6 & 276,71 \\
\hline Chile & 3,7 & 156,83 \\
\hline
\end{tabular}

Fuente: Censo Mundial de Automóviles (1926).

La acelerada difusión del automóvil en la Argentina implicó también el advenimiento de lo que John Urry ha llamado la "automovilidad": una constelación de nuevas prácticas y sentidos culturales, una cultura conformada en torno al automóvil, a la velocidad y al movimiento (Urry, 2000; Featherstone et al., 2005). El viaje por placer en automóvil tuvo un papel protagónico en la temprana automovilidad, pero sus características se transformaron a partir de fines de los años de 1920 y comienzos de los de 1930, cuando fue adoptado por los sectores medios y se volvió una actividad más previsible y mercantilizada. Esos cambios coincidieron en la Argentina con el desarrollo del "turismo nacional”, una práctica moderna que implicaba un desplazamiento dentro del país con fines recreativos por un período acotado de tiempo, asociada a la generalización de las vacaciones en los usos de los profesionales liberales y los sectores medios de comerciantes o industriales, primero, y los asalariados, después.

Este trabajo analiza la configuración en la Argentina de la primera mitad del siglo $\mathrm{xx}$ del turismo en automóvil como una nueva práctica de ocio y de consumo, como parte de un proceso en el que se entrelazaron la democratización social del consumo de automóviles, la expansión del turismo nacional, la transformación técnica de los vehículos y la construcción de infraestructura vial. 
Nuestra perspectiva abreva a la vez en una serie de campos de investigación relativamente nuevos. Por un lado, en los estudios sobre la historia de la movilidad y el transporte, a los que en parte hemos hecho ya referencia. La perspectiva del mobility turn invita a pensar de forma holística al movimiento como un entramado de los movimientos físicos de personas, bienes e información, sus significados y las experiencias de los sujetos, en múltiples escalas que van del cuerpo al planeta (Cresswell, 2006). En segundo lugar, se liga al campo de la historia del turismo, una de las prácticas de las "culturas móviles" modernas. Dentro de este campo, algunos estudios han analizado los viajes turísticos, destacando sus vinculaciones con la afirmación de las identidades nacionales (Pirie, 2009) o sociales (Furlough, 1998; Harp, 2002) y la dimensión de la experiencia y sus representaciones (Zilcosky, 2008). Finalmente, este trabajo se nutre de las investigaciones sobre el consumo, un campo transversal que ha enriquecido la mirada sobre diversas problemáticas sociales, económicas y culturales, señalando la necesidad de contemplar las dimensiones simbólicas del consumo de bienes, servicios y experiencias (De Grazia, 2009).

Los viajes en automóvil han atraído recientemente la atención de algunos investigadores. Han sido estudiadas las aventuras de los pioneros en automóvil y sus relatos, pero también ha emergido cierto interés por analizar la conformación en la entreguerra de prácticas más regulares y socialmente más difundidas de viaje en carretera. Así, por ejemplo, Gijs Mom (2011) ha analizado para el contexto europeo el turismo en automóvil en la entreguerra como parte de las transformaciones que condujeron a una "domesticación" del automóvil a partir de su difusión entre la pequeña burguesía. Para Mom estos cambios se vincularon directamente con las transformaciones técnicas que hicieron del auto un espacio sensorialmente más aislado del entorno y que facilitaron la tarea del conductor permitiéndole el consumo estético del paisaje.

En Latinoamérica todas estas cuestiones han recibido atención escasa: la historia del turismo se ha concentrado predominantemente en el estudio de localidades turísticas (Booth et al., 2002; Pastoriza y Zuppa, 2004) y, en los últimos años, de las políticas públicas (Pastoriza, 2011; Piglia, 2014), mientras los estudios sobre historia de la movilidad están aún en su infancia. En particular el turismo en automóvil ha sido poco estudiado. Se encuentran, sin embargo, algunas interesantes excepciones. Así, el trabajo pionero de Guillermo Giucci (2007), por ejemplo, se ha enfocado en el análisis de las representaciones del automóvil en la literatura, la prensa y el cine (incluyendo las de los viajes de los pioneros), y avanzado en la construcción de una historia cultural del automóvil en Latinoamérica. Más recientemente, desde la antropología, Rosa Ficek (2015) se ha ocupado de las experiencias y representaciones de los viajeros nortemericanos que han recorrido la Carretera Panamericana, mientras el 
historiador J. Brian Freeman ${ }^{2}$ ha abordado el "circuito Caribe" de la misma carretera y los viajes de turistas norteamericanos a México y a Cuba hasta los años sesenta del siglo xx. Por su parte, el caso argentino ha sido abordado de forma lateral por los trabajos de Anahí Ballent (2005) sobre la construcción de un “imaginario del camino" en la Argentina y de Melina Piglia (2014) sobre el Automóvil Club Argentino (ACA).

Este trabajo se propone estudiar la emergencia del turismo en automóvil en la Argentina de la primera mitad del siglo xx, una práctica turística que mezcló hedonismo y patriotismo. La perspectiva escogida apunta a situar los orígenes del turismo en automóvil en el cruce entre la movilidad social ascendente, la afirmación de nuevos hábitos y prácticas de consumo, los cambios técnicos en los vehículos y los avances de la integración nacional material y simbólica. Nos hemos basado en una serie de fuentes editas (publicaciones periódicas de los clubes de automovilistas, revistas y memorias de los organismos oficiales de Parques Nacionales y Vialidad), pero también en los recuerdos y fotografías personales de algunas familias, fruto de un trabajo de recopilación que está en sus inicios pero que puede resultar clave para una futura historia cultural de las prácticas del viaje en la Argentina.

\section{Autos, caminos y clubes de automovilistas}

La Argentina se había convertido entre 1880 y 1930 en una muy exitosa exportadora de carne vacuna y cereales. Esta actividad generó un enorme volumen de riqueza que, aunque en un marco de fuerte desigualdad social, produjo una profunda transformación en la economía y la sociedad, impulsando la construcción de ferrocarriles y puertos, estimulando la masiva llegada de inmigrantes y el rápido crecimiento de las ciudades del litoral como Buenos Aires o Rosario. Otra de las consecuencias de estas transformaciones fue un marcado proceso de movilidad social, favorecida además por una política que extendió activamente el acceso a la educación primaria, lo que contribuyó además a generar una cultura moderna y abierta a las novedades técnicas, sobre todo en las ciudades (Sarlo, 1992).

En el contexto de esta sociedad cosmopolita y móvil, fascinada con las novedades técnicas, el número de vehículos automotores creció acentuadamente desde 1923, alcanzando valores relativos similares a los europeos (Tabla 1). Para 1928 circulaban alrededor 300 mil automotores en la Argentina, más del 70\% de ellos automóviles particulares, y entre 1942 y 1945, unos 450 mil (Tabla 3). La mayor parte de estos automóviles se encontraba en las ciudades, ya que desde principios de siglo la po-

\footnotetext{
2. J. Brian Freeman, conferencia "La Carretera Panamericana, el circuito del Caribe y el turismo Norteamericano en México y Cuba, 1898-1961”, en Unam, Ciudad de México, 12/9/2011.
} 
blación argentina tendió a ser marcada y crecientemente urbana; por otro lado, en torno de las ciudades se hallaban los pocos caminos de tránsito permanente.

TABLA 3

Automotores en Argentina.

\begin{tabular}{lc}
\hline AÑO & CANTIDAD \\
\hline 1901 & 129 \\
1914 & 15.965 \\
1918 & 41.698 \\
1921 & 53.676 \\
1925 & 160.632 \\
1930 & 344.169 \\
1935 & 270.296 \\
1940 & 316.522 \\
1942 & 450.000 \\
\hline
\end{tabular}

Fuente: "Estadística mundial de automóviles" (1923, 1927); Dirección Nacional de Vialidad (1940, 1942)e ACA (1940b).

Si bien había miles de nuevos automovilistas cada año en la Argentina, el desarrollo vial era muy pobre, aún comparado con otros países latinoamericanos. Así, por ejemplo, en 1926 Argentina contaba con $1.200 \mathrm{~km}$ de camino "posible", unos 0,008 kilómetros por cada vehículo a motor que circulaba en el país; Chile en cambio, que tenía menos del 10\% del volumen de automotores de la Argentina, poseía más del doble de la extensión de caminos en buen estado, lo que daba una proporción de 0,35 kilómetros de camino por vehículo ("La América Latina construye”, 1927, p. 864).

En ese marco, y siguiendo el ejemplo europeo y norteamericano, los primeros automovilistas argentinos se nuclearon en clubes sociales y deportivos para intercambiar información y mejorar las condiciones de uso de los autos: El Automóvil Club Argentino (1904) y el Touring Club Argentino (1907) procuraron la mejora de la vialidad y la difusión del turismo nacional y llegaron incluso por momentos a reemplazar a la casi inexistente burocracia vial, construyendo algunos caminos para automóviles ${ }^{3}$.

Salir de la ciudad con el auto era, por esos años, toda una aventura. Los vehículos tenían poca autonomía y se rompían con frecuencia; los caminos eran de tierra y

3. El Touring Club construyó, por ejemplo (con dineros públicos y privados) los caminos de Buenos Aires a las localidades de Olivos y La Plata. 
como generalmente carecían de desagües, era muy frecuente que se formaran pantanos ante la menor lluvia, de los que debían ser liberados con auxilio de animales de tiro; los ríos y arroyos sumaban obstáculos, ya que los puentes eran muy escasos.

Para mediados de los años de 1920, la multiplicación del parque automotor, los cambios técnicos de los autos y su consagración como medio de transporte, agudizaron la necesidad de caminos firmes y lisos, cuya ejecución excedía las capacidades de los clubes de automovilistas. El Estado nacional comenzó entonces muy tímidamente a construir algunos caminos (como el comienzo de la ruta entre las ciudades de Buenos Aires Rosario y Córdoba), y algunas provincias también procuraron mejorar sus caminos internos. Así, por ejemplo, la provincia de Córdoba, un destino de turismo serrano ya consagrado, comenzó a ofrecer a los turistas (la mayoría de los cuales había traído sus vehículos en ferrocarril) la posibilidad de recorrer numerosos circuitos en automóvil, mejorando sus caminos y modificando su legislación impositiva para eliminar gravámenes anticuados como el derecho de piso, que encarecían la estadía de los turistas ${ }^{4}$.

En ese nuevo contexto, ambos clubes de automovilistas (que sumaban entre los dos más de 60 mil socios, equivalente a uno por cada siete automóviles en circulación), se lanzaron de lleno a una campaña de movilización de la opinión pública y de presión sobre el Estado para que construyera una red nacional de caminos (Piglia, 2014, cap. 4). Pero, además, llevaron adelante tareas fundamentales que hicieron realmente posible el turismo en automóvil. El caso del camino directo de Buenos Aires a Mar del Plata, el principal balneario del país, es un buen ejemplo (Figura 1)5.

Construido a partir de una serie de caminos y huellas locales, siguiendo el recorrido del ferrocarril y atravesando estancias, adquirió su entidad como tal en buena parte a través de las acciones del Automóvil Club: sus dirigentes lo recorrieron en automóvil en 1922, los, señalizaron y levantaron su primer plano. Tras gestionar ante la provincia de Buenos Aires y los municipios algunas reparaciones fundamentales, en enero de 1925 se organizó la primera caravana de turistas y, para fines de la década del 1920, el club tenía montada toda una infraestructura que hacía practicable el viaje en automóvil al balneario: casillas camineras que proveían de combustible, repuestos y refugio los viajeros, una estación de descanso en la localidad de Maipú (a $150 \mathrm{~km}$ de Mar del Plata), una pasarela para el cruce del río Samborombón y el servicio de un

4. Inicialmente todas las localidades cobraban a los viajeros por la estadía de sus autos en la jurisdicción.

5. Mar del Plata había surgido a fines del siglo xIX como un resort para la élite, al estilo de los balnearios de la Costa Azul. Situada a algo más de 400 kilómetros al sur de Buenos Aires, y conectada a ella por el ferrocarril, comenzó a recibir turistas menos encumbrados ya desde la segunda mitad de los años veinte, un proceso que se profundizó en los años treinta y sobre todo en los años del gobierno peronista (19451955) (Pastoriza, 2011). 
FIGURA 1

La Ruta Nacional 2 Buenos Aires - Mar del Plata

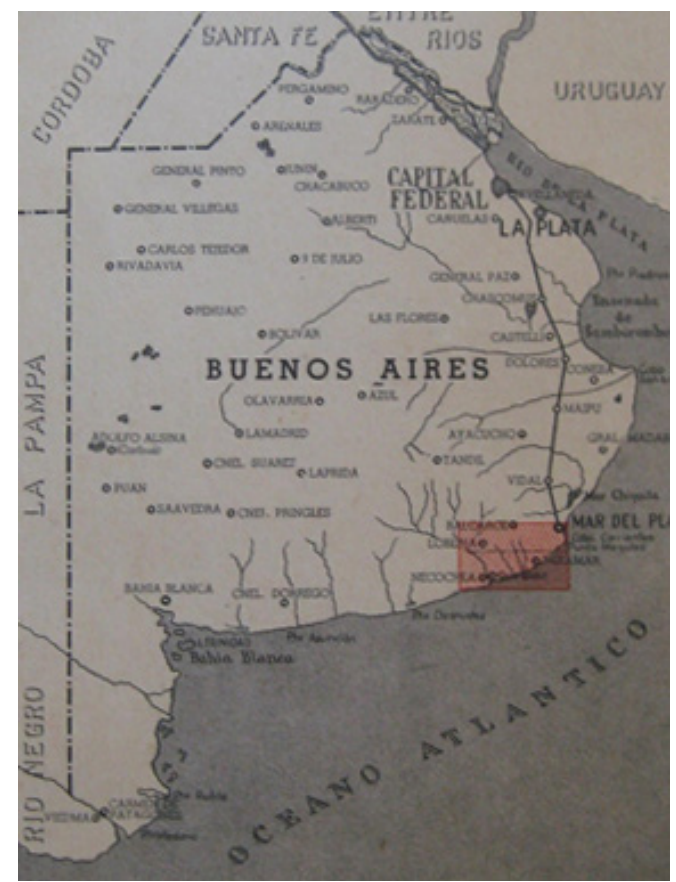

Fuente: ACA (1940a).

coche "piloto" que salía y regresaba todas las semanas durante la temporada estival guiando a caravanas de veraneantes.

El panorama cambió sustancialmente en los años de 1930, que fueron un período de avance de la intervención del Estado en la sociedad y en la economía. Se emprendió una política caminera mucho más decidida y sistemática, fundada en la planificación a nivel nacional y dotada de nuevos recursos económicos. La Dirección Nacional de Vialidad, creada en 1932, puso en marcha un plan sistemático de construcción de una red de caminos troncales (nacionales), sostenido con un impuesto a la nafta y los lubricantes. A la vez, la Dirección financiaba y supervisaba la construcción de las redes provinciales de caminos, que complementaban la red troncal. La inversión en caminos se quintuplicó.

El objetivo central era volver más barato el transporte hasta los puertos de los productos que Argentina exportaba, para mejorar los beneficios de los productores golpeados por la depresión mundial de los años treinta. En ese marco, los caminos "productivos" tuvieron prioridad (con la excepción, tal vez, de la ruta a Mar del Plata). Por otro lado, como los recursos eran limitados y el tránsito en muchas zonas era relativamente bajo, se prefirió construir una mayor extensión de caminos de menor 
FIGURA 2

Rutas Principales y Estaciones de Servicio ACA-YPF en 1943

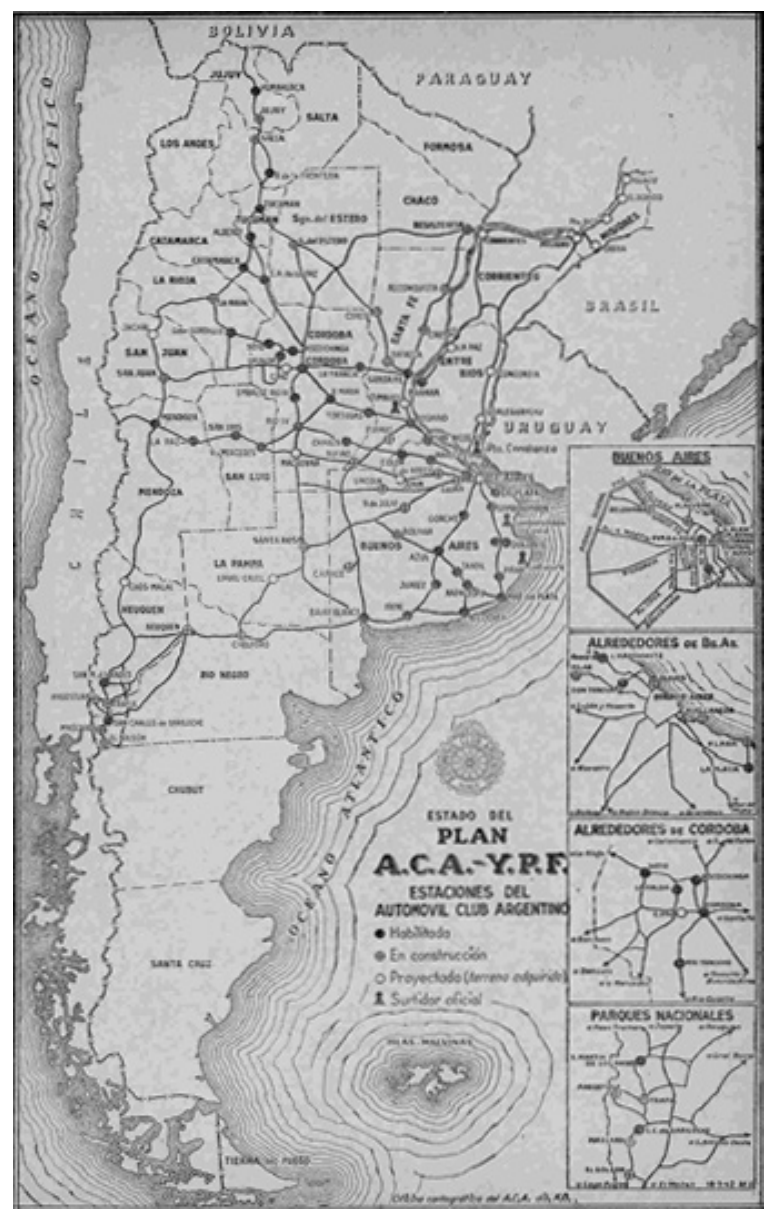

Fuente: ACA (1942).

calidad (de tierra con mejoras), invertir en su mantenimiento permanente e irlos mejorando poco a poco de acuerdo con las necesidades del tránsito.

La obra realizada fue espectacular y los 2 mil $\mathrm{km}$ de caminos permanentes de 1932 se convirtieron en más de 30 mil en 1944 (Ballent y Gorelik, 2002, p. 159). Si bien la malla de los caminos nacionales reproducía, con sus insuficiencias, el trazado de las vías férreas, la construcción simultánea de caminos provinciales financiados con ayuda federal, densificó la trama vial (Figura 2).

Estas obras se completaron durante los años del gobierno peronista (1946-1955) que pavimentó varias rutas importantes y mejoró la red de caminos provinciales. En el caso de la provincia de Buenos Aires, esto potenció las posibilidades para el excursionismo, conectando a Buenos Aires y a la capital provincial (La Plata), pero también a las localidades serranas del centro agroganadero, con la costa del río de La 
Plata, con la costa atlántica y con las lagunas de la Provincia, atractivas para quienes practicaban la pesca deportiva. Estos caminos estimularon además el desarrollo de nuevas localidades balnearias al norte de Mar del Plata (Figura 1). Relativamente alejados de los trazados férreos, estos balnearios nuevos eran sobre todo accesibles en automóvil.

Las estaciones de servicio eran el complemento necesario de esta red de caminos. El Automóvil Club firmó a mediados de 1936 un provechoso convenio de exclusividad para la venta de los productos de la compañía petrolera estatal (Yacimientos Petrolíferos Fiscales, YPF) que, a cambio, le otorgó de un crédito en productos gracias al cual pudo construir casi ochenta estaciones de servicio en todo el país entre 1937 y 1943 (Figura 2) más de noventa para mediados de los años de 1950. Esta primera red nacional de estaciones de servicio fue clave en la puesta en uso de muchas de las nuevas vías como la ruta pavimentada a Mar del Plata, la que atravesaba la región de Cuyo y llegaba hasta la frontera con Chile o la ruta del Noroeste (Figura 2) (Piglia, 2013).

La Segunda Guerra frenó el avance de la automovildad. Por un lado, se detuvo la importación de automotores, y su número quedó congelado hasta por lo menos 1946 y luego creció muy lentamente debido a la escasez de divisas. En segundo lugar, cesó la importación de caucho y de neumáticos y su venta tuvo que ser racionada en 1942. Finalmente, ese mismo año, YPF se vio forzado a racionar los combustibles líquidos, Bajo el racionamiento los viajes de turismo podían hacerse si se informaban con anticipación y se solicitaban cupones de nafta para el trayecto de ida y vuelta. El sistema reemplazado en 1946 por el "ordenamiento" que establecía cuotas semanales, para cada auto, asignándole un surtidor y un día de carga fijo.

El auto para el placer

Todavía muy distantes de Estados Unidos en cuanto a las cifras de difusión de automóviles, los nuevos vehículos eran en Alemania o Francia, como en Argentina o en Uruguay, solo eran accesibles para los sectores medios y altos. Como en Europa, entonces, en Argentina el consumo de automóviles estaba atravesado por la búsqueda de la distinción social, pero también por el hedonismo. Las publicidades de vehículos, combustibles o lubricantes reflejaban esta representación enfatizando las posibilidades de goce asociadas al automóvil, por sobre sus ventajas prácticas.

\section{Excursionismo}

"El domingo ha dejado de ser el día del Señor para mudarse en el del automóvil", sostenía un columnista de la revista El Hogar en 1933, reflejando el fenómeno 
FIGURA 3

Excursión Familiar a Luján en 1938

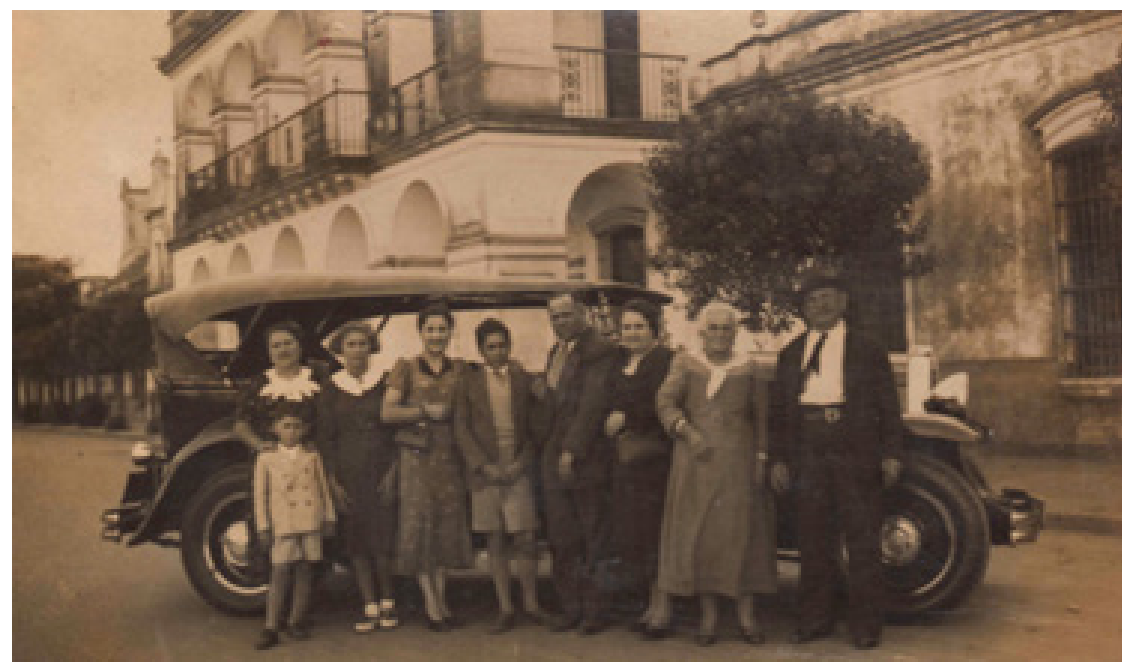

El hombre más joven estaba casado con una de las hermanas mayores. Era taxista y propietario del único automóvil de la familia.

Fuente: Archivo personal.

cada vez más extendido del excursionismo (Cancela, 1933, p. 13). Mientras un creciente - pero todavía reducido - número de turistas se aventuraba a realizar trayectos largos en automóvil, la mayoría se aficionaba a los paseos por los alrededores de la ciudad, visitando localidades cercanas, estancias, parques o balnearios de río, laguna o mar.

Los destinos del excursionismo se multiplicaron en los años de 1930 y 1940, impulsados, entre otros factores, por una acción deliberada de los gobiernos provinciales, que veían en el turismo una fuente posible de prosperidad para las localidades y en la recreación popular "saludable" y "educativa” una forma de control social. Así, el gobierno de la provincia de Buenos Aires invirtió a fines de los años treinta en la construcción de atractivos turísticos como parques-museo históricos (en las localidades de San Antonio de Areco, Dolores y Chascomús) y de obras monumentales en una veintena de municipios. En ese marco, se encaró, por ejemplo, la "urbanización” de la localidad de Luján ${ }^{6}$, un lugar frecuentado por los excursionistas en automóvil atraídos por la Basílica y por las posibilidades de recreación junto al río (Figura 3).

6. Luján se encuentra a $70 \mathrm{~km}$ de la ciudad de Buenos Aires, sobre un camino frecuentado ya desde tiempos coloniales. Su santuario atraía peregrinos desde el siglo XVII, y en 1910 se inauguró la Basílica (cuya obra se completó en 1935). 
FIGURA 4

Grupo de Excursionistas de la Ciudad de Maipú en Mar del Plata, 1939

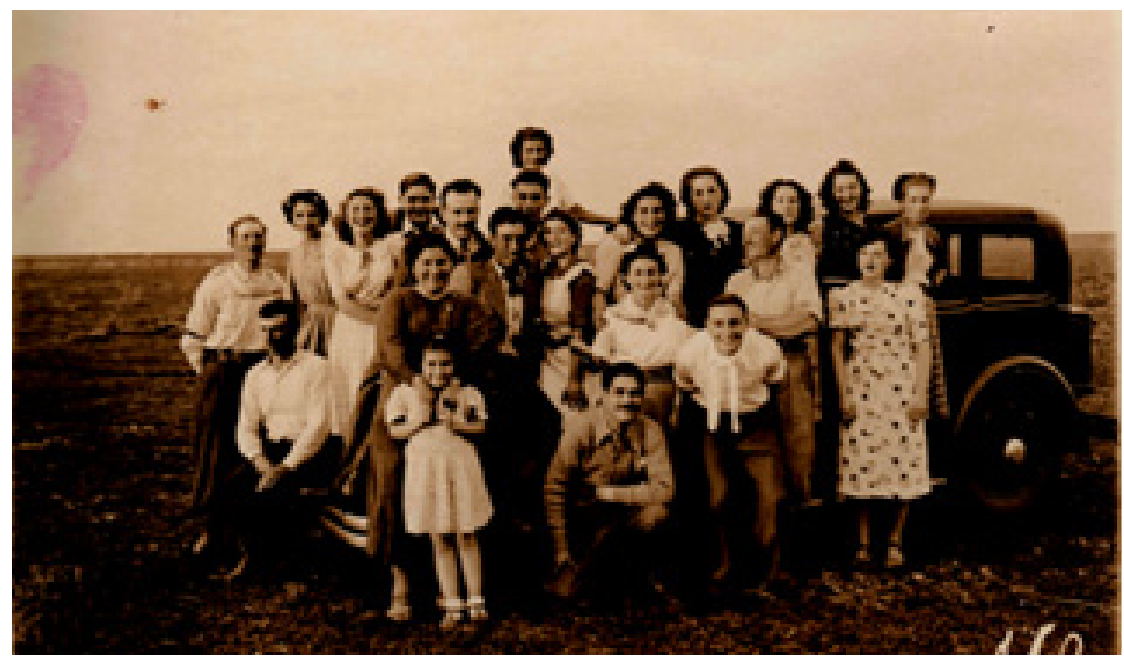

Fuente: Archivo Familia Duclós.

Como vimos, el gobierno provincial encaró además la construcción de caminos para el excursionismo en automóvil, como el camino costanero entre los balnearios de Mar del Plata y Miramar (1938), un parkway pensado para el consumo visual del paisaje pero además para la práctica del pic-nic o la pesca desde las barrancas (Figura 4).

El excursionismo en automóvil se volvió también, a fines de los años de 1930 y a principios de los años de 1940, patrimonio de las capas más altas de los sectores populares: el mismo automotor que se utilizaba para trabajar durante la semana (el taxi o el pequeño camión de reparto, propio o no) podía servir para llevar familia y amigos de paseo a los alrededores de la ciudad (Figura 3); en ocasiones especiales, además, podía alquilarse un coche para pasear.

El turismo excursionista en automóvil, por el día o el fin de semana, se asoció, potenciándolas, con una serie de prácticas recreativas al aire libre que se habían difundido sobre todo en la primera posguerra, como el camping, el pic-nic y la pesca deportiva. Combinaba experiencias de consumo visual de lugares turísticos y paisajes, con un turismo de acción, en el que el automóvil cumplía un papel diferente, acercando (y multiplicando por su flexibilidad) escenarios para esas prácticas (lagunas, arroyos, riberas de ríos, parques etc.) pero también facilitando el transporte de los implementos necesarios para ellas (cañas de pescar, mesas y sillas, carpas, catres, canastos, termos, vajilla etc). El resultado fue la proliferación de la oferta de estos 
FIGURA 5

Nuevos Consumos: El Automóvil, el Campingy el Pic-nic

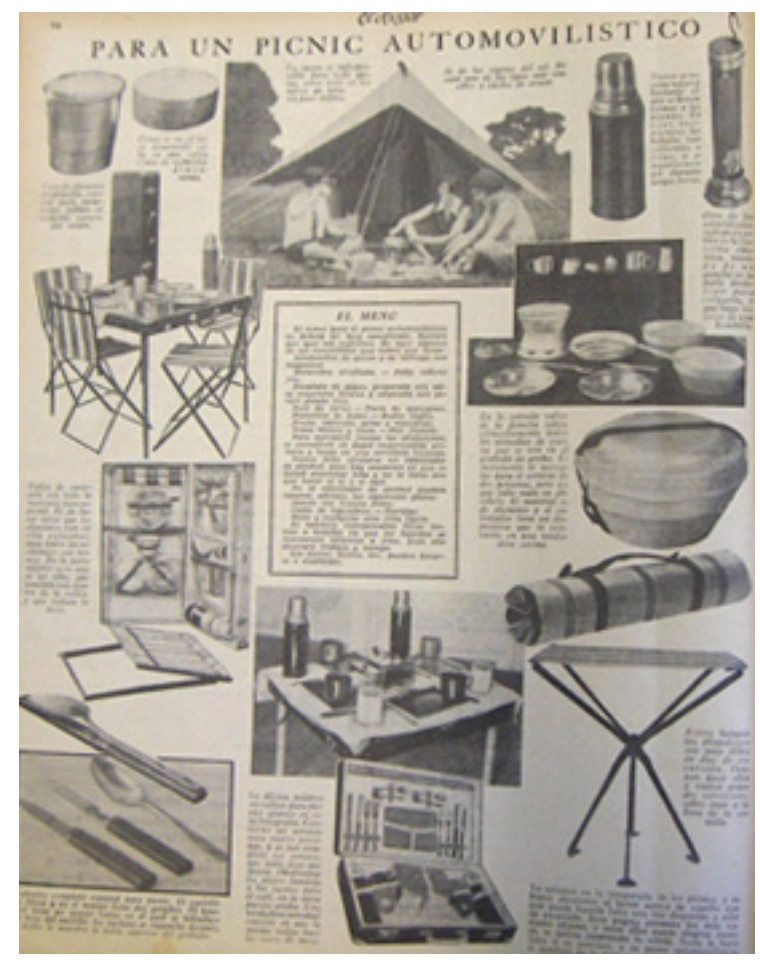

Fuente: El Hogar (1931).

bienes (Figura 5), que se desarrollaron en muchos casos pensados específicamente para su traslado en automóviles - como los "acoplados de turismo" y casas rodantes de principios de los años cuarenta (Figura 6) - y la multiplicación de su consumo.

En los años de 1920 el excursionismo en automóvil había implicado una fuerte dosis de aventura (por los desperfectos de los autos, los empantanamientos y los extravíos), conjurada en muchos casos con excursiones colectivas organizadas por alguno de los clubes de automovilistas. En los años de 1930, en cambio, la mejora en paralelo de los automóviles y de los caminos periurbanos dio lugar a una práctica mucho más previsible, marcada por el goce estético del paisaje o hedonístico de las actividades de ocio y atravesada por el mercado. Se trataba, como otras actividades turísticas, de una práctica prefigurada y moldeada por guías, folletos, revistas y hojas de ruta. Los destinos del excursionismo se fueron formalizando y se desarrollaron en ellos infraestructuras (predios parquizados, fogones, muelles, caminos, monumentos, museos) y servicios (alquileres de botes y equipos de pesca, de caballos para paseos, de mesas, bancos y fogones, servicios de fotografía, proveedurías, hosterías, confiterías y otros servicios de gastronomía y alojamiento). 
FIGURA 6

Nuevos Consumos: Acoplados de Turismo

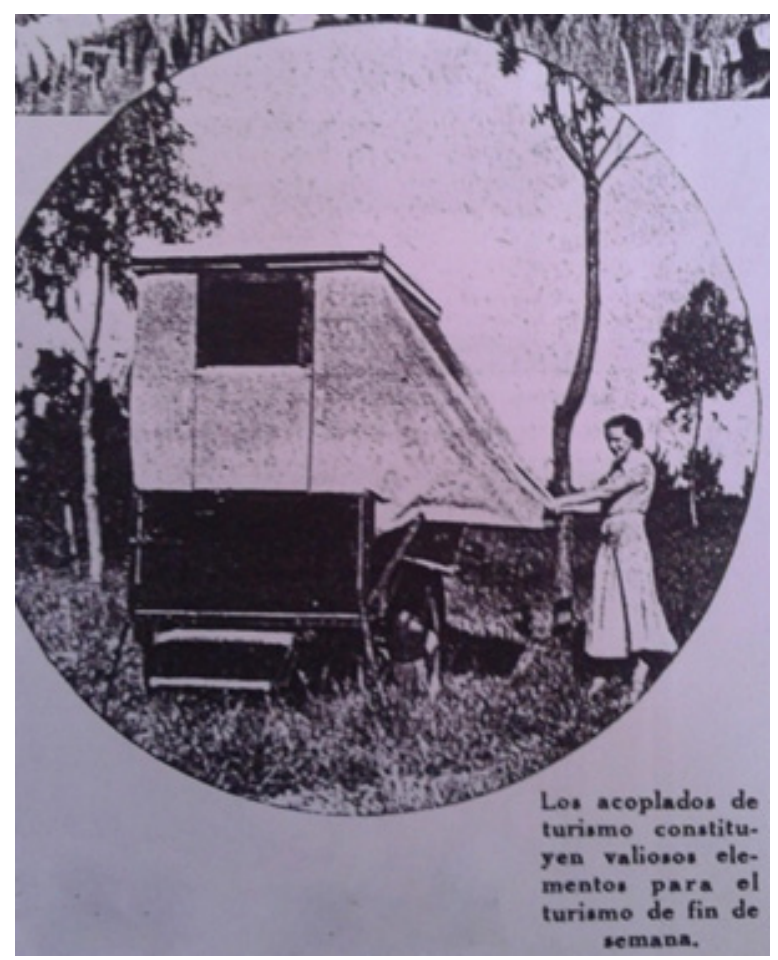

Fuente: "El week-end, propulsor del turismo" (1941).

El Automóvil Club Argentino alentaba particularmente estas prácticas, organizando paseos, campamentos y excursiones de pesca y adquiriendo, forestando y equipando predios para el recreo ${ }^{7}$.

\section{Viajeros y turistas}

Durante los años de 1920, los viajes de media y larga distancia en automóvil eran aventuras de osados pioneros, cuyos relatos muchas veces eran objeto de publicaciones en la prensa periódica o en libros. En la segunda mitad de la década, sin embargo, comenzó a desarrollarse el turismo en automóvil propiamente dicho. Dos rutas concitaron la mayor parte del interés. Por un lado, el camino de Buenos Aires a Rosario y Córdoba; por el otro, el camino de Buenos Aires a Mar del Plata. Ambos

7. El Automóvil Club buscaba promover la práctica del “camping”, expresión por la que entonces se entendía pasar un "día de campo". Para 1930 el club poseía cinco predios, en San Miguel (sobre el camino a Luján), a orillas de la laguna de Chascomús, en Luján, en Quilmes y en Punta Chica (balnearios de río) (Piglia, 2008). 
FIGURA 7

El Auto en Primer Plano: Viajero en Puerto Perito Moreno en el Lago Nabuel Huapi, Diciembre de 1936

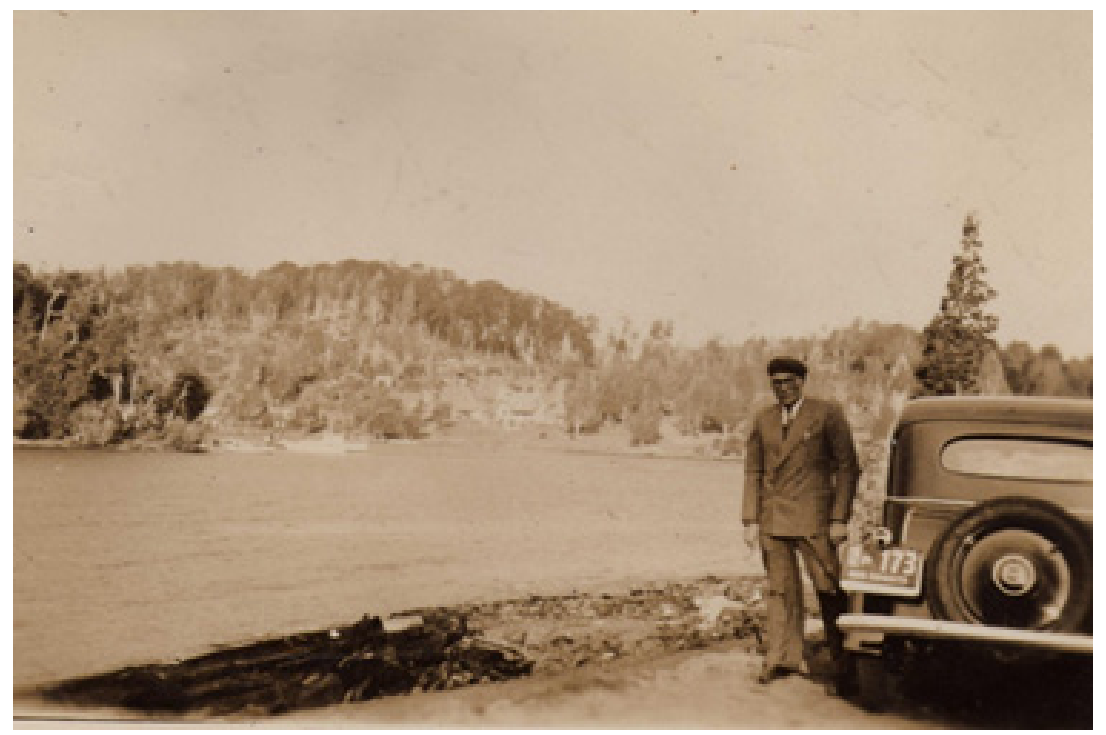

Fuente: Archivo personal. Donación de Luis Jorge Giménez.

fueron relevados, señalizados y mejorados por el ACA, que mantenía surtidores y estaciones de descanso, pero continuaban siendo todavía bastante exigentes para máquinas y automovilistas. Para fines de los años veinte el camino a Mar del Plata, aunque estaba bastante frecuentado y bien mantenido, demandaba más de diez horas de viaje, era practicable solo en verano y presentaba numerosas dificultades, como la presencia de pantanos ante la menor lluvia ${ }^{8}$ : pocos automovilistas se arriesgaban a emprender solos la travesía.

El turismo de media y larga distancia en automóvil adquirió una escala más considerable recién a partir de la construcción de la red nacional de caminos, cuyas rutas principales estaban ya en uso a fines de los años treinta. Las cifras de arribos en automóvil a Mar del Plata, dan cuenta de este cambio: mientras en la temporada 1935-1936 (antes de la inauguración de la ruta pavimentada) solo un 18\% de los viajeros llegó a la ciudad en automóvil; más del 50\% lo hizo por ese medio en la temporada 1940-1941 (Pastoriza, 2011, p. 276).

El automóvil se convirtió en una alternativa al ferrocarril para el viaje a destinos turísticos de larga trayectoria como Mar del Plata, Córdoba y Mendoza, pero también permitió el desarrollo de nuevos centros de turismo, como los ya mencionados

8. En tren el viaje demoraba alrededor de seis horas y resultaba muy confortable. 
FIGURA 8

El Auto en Primer Plano: Madre y Hijo en el Limite entre las Provincias de Buenos Aires y Santa Fe

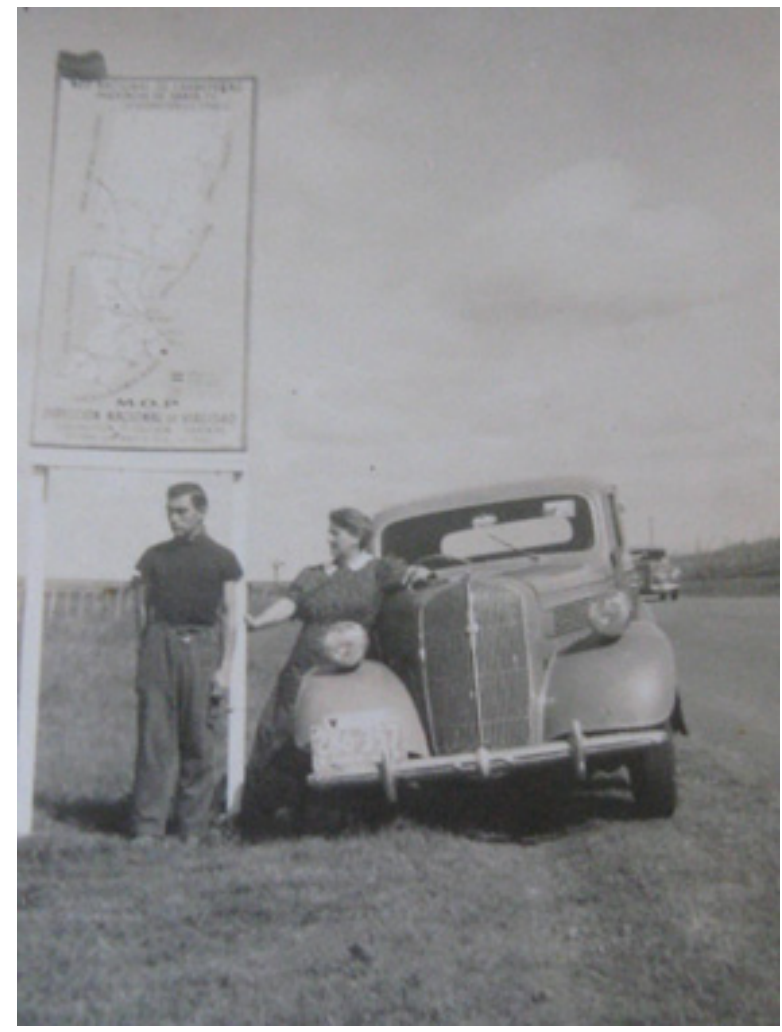

Viaje de la familia Giménez-Rípodas de Coronel Vidal (provincia de Buenos Aires) a la frontera con Chile en Mendoza en marzo de 1942.

Fuente: Archivo Luis Jorge Giménez.

balnearios de la costa atlántica al sur y al norte de Mar del Plata a los que el ferrocarril nollegaba. En ellos se instalaron campamentos, pequeños hoteles y hosterías y fueron sede de un floreciente negocio inmobiliario basado en la venta de lotes para segundas residencias a sectores medios (Bertoncello, 1993; Ballent, 2003).

El turismo en automóvil también permitió que localidades que contaban con menos atractivos e infraestructura para sostener una estadía larga, explotaran un turismo de paso, integrándose en circuitos más amplios: fue el caso de algunos pueblos y ciudades de la región de Cuyo - las provincias de Mendoza, San Juan y Tucumán - o del Noroeste (Ballent, 2003). En las décadas siguientes se incorporarían destinos más lejanos al completarse la pavimentación de las rutas nacionales e internacionales y dotarse a esas rutas de servicios de asistencia y carga de combustible: el Noreste (con las Cataratas del Iguazú como atractivo máximo), la región de los lagos del sur o el cruce hasta Chile se sumaron como destinos posibles para los viajes (Figuras 7 e 8 ). 
La difusión del automovilismo coincidió en la Argentina con el acceso a las vacaciones de los sectores medios. Frente al veraneo de las élites, el turismo de los sectores medios se caracterizaba por sus restricciones en el tiempo y en los recursos que podían invertirse en él y dio lugar a prácticas recreativas novedosas, en las que el automóvil tuvo un rol preponderante. La difusión de esta práctica entre los nuevos automovilistas implicó una labor pedagógica que el Touring Club y el Automóvil Club abrazaron como uno de sus deberes principales.

Era necesario, en primer lugar, convencer a los potenciales turistas de que el viaje por placer en automóvil, ciertamente más incómodo, lento y azaroso que el viaje en ferrocarril, era posible y sobre todo deseable. Uno de los dispositivos centrales en esta pedagogía de los viajes en automóvil fueron las guías de viaje, que comenzaron a publicarse a comienzos de los años de 1940, junto a las más breves "cartas de turismo" (que contenían el mapa de una ruta, el plano de la ciudad de destino, e información turística). Estos dispositivos anticipaban lo que el viajero podía encontrarse en el camino reduciendo la incertidumbre, pero también modelaban la práctica turística dando cuenta de qué visitar, cómo gozar de esos atractivos (por ejemplo, estableciendo "miradores") e incluso cómo sentirse ante alguno de ellos. La primera guía de viaje publicada por el aca, indicaba a los turistas debajo del nombre de la localidad, la lista de servicios disponibles y luego, la de los sitios de interés - si el club consideraba que los había: "Jesús María [...] ver: bosques de nogales y naranjos, restos de construcciones del siglo XVIII, ruinas donde velaron a Quiroga en Sinsacate" (ACA, 1942, p. 166)9.

Las cartas de turismo brindaban orientación al automovilista para llegar al destino, pero además lo orientaban sobre las prácticas recreativas y excursiones (el "hacer" en vacaciones) que llenarían los días de una estadía más larga. Así, por ejemplo, en la carta del turismo de Mar del Plata del ACA se proponía la visita a Laguna La Brava o al balneario y laguna de Mar Chiquita, donde se podía practicar la pesca o alquilar caballos (ACA, 1940). Más amplias, las guías, como la de Zona Centro del ACA de 1942, proponían más bien un turismo de circuito que hacía eje en el consumo visual de los paisajes (pasear, recorrer, visitar) (Urry, 2002). El tipo de práctica que todos estos materiales sustentaban estaba en claro contraste con los viajes de descubrimiento de la patria de las élites, individuales, inéditos, narrados en clave sublime (Elflein, 1917).

Las guías y cartas de turismo, del mismo modo que los relatos de viajes, los artículos informativos en revistas y periódicos y también las carreras en carreteras (desde 1937 con automóviles que al menos exteriormente se parecían a los de uso

9. Algo similar ha mostrado Harp (2002) en su análisis de las guías Michellin, y la constitución de un mapa turístico-gastronómico nacional en Francia en las primeras décadas del siglo Xx. 
corriente) que se volvieron muy populares en los años de 1940, fueron elementos centrales en la construcción de nuevas representaciones sobre el viaje en automóvil y en la producción de los paisajes a ser consumidos por los turistas (Urry, 2002). A la vez, estos dispositivos, junto a las postales y fotografías que circularon profusamente en la entreguerra, contribuyeron decisivamente a canonizar a una serie de destinos como paisajes nacionales, a integrar desde el punto de vista simbólico al territorio nacional y a construir y fijar los modos de ver y de gozar de los atractivos turísticos y de enlazarlos para montar recorridos patrióticos.

¿Por qué viajar en automóvil? Los argumentos puestos en juego eran de variado cuño. Se enfatizaba la independencia y la libertad, uno de los valores nucleares ligados al automóvil desde su comienzo: así, por ejemplo, refiriéndose a la inauguración del camino de la ciudad de Mendoza a las termas de Cacheuta, el Automóvil Club celebraba la situación de los automovilistas, librados de las "tiranías que imponen los horarios del ferrocarril" (Revista ACA, 1928). Al permitir un viaje "libre", individual o familiar; el turismo en automóvil participaba, además, del ideal de domesticidad de los sectores medios, marcado por el énfasis en la privacidad y la centralidad de la familia (Liernur, 1999). La aventura no era tampoco un componente menor como argumento en los primeros tiempos, sobre todo en un contexto en el que la práctica se consideraba todavía un deporte y las emociones fuertes, una forma de vivificación de los espíritus entumecidos por la vida moderna.

El patriotismo era otro argumento importante en la prédica en favor del turismo nacional. Aplicado al turismo en automóvil, el discurso patriótico promovía sobre todo un modelo de viaje en el que el objetivo era el propio recorrido, más que el destino final. Una ruta o un circuito que articulaba una serie de hitos y vistas patrióticos, ya fueran estos rasgos naturales, restos del pasado nacional o colonial o muestras de la pujanza y el progreso nacional ${ }^{10}$. Así, sobre todo a partir de los años de 1940 y 1950, un creciente número de familias se lanzó a estos recorridos turístico-patrióticos sobre la base de la ruta pavimentada a Mendoza o de la que llevaba, pasando por Córdoba, a las provincias del Noroeste (Tucumán, Salta y Jujuy) (Ballent, 2003). Las fotografías familiares de estos viajes, conservadas en miles de hogares argentinos, dan cuenta de la centralidad del auto y del camino: en la gran mayoría el automóvil es protagonista, junto al paisaje o la señal caminera, las pruebas de que se han recorrido y conocido los lugares apropiados, a los que se ha llegado con el esfuerzo de la máquina y del conductor (Figuras 7 e 8 ).

10. Este catálogo de los atractivos "nacionales", construido por la prensa y las guías de viaje, fue asumido más tarde por el Estado en su propaganda oficial. Véase por ejemplo el estudio de Carla Lois y Claudia Troncoso (2004) sobre la propaganda turística peronista. 
Aún donde la ruta en sí no resultaba tan interesante, como en el caso del camino hasta Córdoba, el viaje en automóvil, que llevaba casi dos días, se presentaba como un camino de descubrimiento de la Patria en otro sentido: el contacto con la "gente amable" del interior, serviciales, sencillos, que nacionalizaba a los cosmopolitas habitantes de Buenos Aires. Así, por ejemplo, en las instrucciones para un viaje a Córdoba en automóvil se simbolizaba ese proceso de encuentro con el mate amargo, bebida nacional, criolla y viril: "Como usted es hombre de la tierra habrá puesto su mate y su bombilla en uno de los bolsillos del cochecito. Dondequiera que llegue, pida una pava de agua caliente y tómese media docena de mates amargos" (El Hogar, 1931, p. 11 $)^{11}$. La llegada a destino, luego de ese viaje transformador, reservaba aún otras recompensas: junto a la emoción patriótica del encuentro con el paisaje (en este caso, las sierras, el cielo "azul cobalto", el perfume de la menta y la hierba buena), la afirmación de la identidad: "Hombres, mujeres y chicos, típicamente criollos, lo mirarán con simpatía y usted se sentirá entre ellos profunda y sustancialmente argentino" (Idem, p. 12).

El turismo en automóvil participaba así, como un eslabón, en el proceso de producción territorial de la Nación, iniciado en la segunda mitad del siglo XIX. Este proceso se fundaba, por supuesto, en la apropiación e integración material del territorio, a través de la extensión de la presencia estatal, del tendido de vías férreas, de conexiones telegráficas y, más tarde, de la construcción de un sistema de caminos permanentes. A la vez, tenía una importante dimensión simbólica: como en otras naciones "jóvenes", desde las décadas finales del siglo xix, una serie de discursos científicos, literarios y políticos cifraron la identidad nacional argentina en las bellezas y riquezas "naturales" del territorio. En esta línea, desde fines de la década de 1910, intelectuales de la élite emprendieron viajes al interior del país, muchas veces en automóvil, en busca de la las "raíces" de la identidad nacional, en momentos en que esta parecía amenazada de disolución, a los ojos de las élites, por las consecuencias de la masiva llegada de inmigrantes ${ }^{12}$. La prensa, las postales, la escuela se encargaron en las primeras décadas del siglo xx de canonizar una serie de paisajes que

11. El mate es una infusión de yerba mate, de consumo muy general en Argentina, Uruguay y Paraguay. Se prepara en una calabaza o recipiente pequeño, en el que se pone una bombilla o sorbete de metal y al que se va añadiendo agua caliente. Lo habitual es que se comparta. En la Argentina es parte inseparable del "folklore" de los viajes en automóvil: los mates a la vera de la ruta, en los descansos o cebados desde un recipiente térmico por un habilidoso acompañante mientras se conduce.

12. Estos viajes se plasmaron en algunos casos en narraciones en la que la clave patriótica se sumaba a la idea heroica del "pioneer" que se aventuraba por rutas difíciles y sublimes paisajes nacionales. Frecuentemente los relatos aparecieron como crónicas seriadas en los periódicos; de hecho, algunos de los viajes fueron directamente auspiciados por periódicos, como es el caso de Ada Elflein, docente y periodista del diario La Prensa (Elflein, 1917) 
FIGURA 9

La Aventura de Viajar a Bariloche en 1938. Viajeros en el Camino entre Choele-Choely Río Colorado

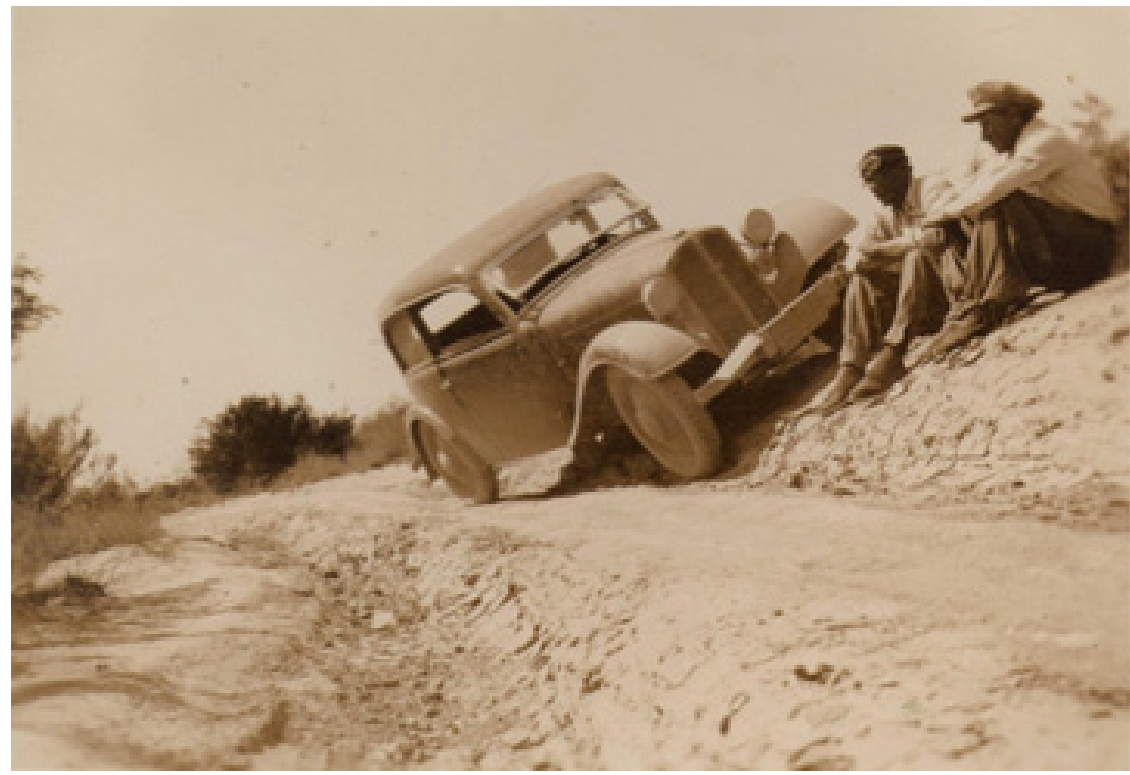

Fuente: Archivo personal, donación de Luis Jorge Giménez.

simbolizaban la potencia de la Nación y los valores de la identidad nacional. Desde los años de 1930, en buena medida en automóvil, los sectores medios responderían a esta apelación a conocer la Patria, en un marco marcado por un proceso en el que los destinos turístico-patrióticos y las prácticas del viaje, se estaban convirtiendo crecientemente en mercancías para el consumo.

Si bien Argentina compartía algunos rasgos de la automovilidad europea (el lugar del auto como vehículo de placer, el perfil social de los poseedores de automóvil), las características de su geografía y de su infraestructura vial, contribuyeron a moldear una cultura del automóvil con características peculiares. En la Argentina, un territorio muy vasto, persistieron hasta por lo menos los años de 1960 espacios poco integrados (el Noreste, la Patagonia), con caminos deficientes y escasos servicios. Eso hizo posible que en la entreguerra coexistieran una experiencia del camino domesticada, previsible y segura, y otra marcada por el riesgo y el "descubrimiento", por la ilusión de la conquista de territorios y caminos casi “vírgenes". Esto, que en parte permite explicar la emergencia de un tipo muy especial de deporte automovilístico en Argentina: el "turismo carretera” (Piglia, 2014, cap. 3) permitió la contemporaneidad de prácticas de viaje de placer en automóvil que en Europa fueron más bien sucesivas (Mom, 2011). 
Así, en 1936, cuando miles de viajeros recorrían con seguridad la ruta a Mar del Plata (cuyo pavimento estaba en construcción), un concesionario de automóviles Rugby de una pequeña localidad de la provincia de Buenos Aires y su amigo técnico vial, emprendieron una aventura riesgosa, que probaba la templanza y habilidad de los hombres y la resistencia de la máquina: el viaje por precarios caminos hasta Bariloche, cruzando los ríos en balsas, llevando combustible en bidones, reparando el automóvil al modo criollo (Figura 9).

La posibilidad de experimentar la sensación de ser "pioneros" se reforzaba por la relativa soledad de la ruta: solo 550 turistas (140 vehículos) llegaron en automóvil entre noviembre de 1937 y marzo de 1938 al Parque Nahuel Huapi, procedentes tanto de Chile como de Buenos Aires; desde Buenos Aires se trataba de una travesía de noventa horas (Dirección de Parques Nacionales, 1938, p. 90). Dos años más tarde, en parte en esos mismos caminos, se llevaba adelante una extensa y desafiante competencia de turismo carretera, el Gran Premio del Sur, que capitalizaba la rudeza de los caminos patagónicos y el riesgo que ello implicaba como desafío deportivo (Piglia, 2014, cap. 3).

\section{Palabras finales}

La difusión del automovilismo en la Argentina fue un proceso casi simultáneo con el desarrollo de lo que podríamos llamar el "turismo nacional”: el automóvil, como vimos, jugó un rol importante en el desarrollo de este tipo de turismo al hacer posible el viaje individual o en familia independiente del trazado vial, estimular una serie de prácticas turísticas nuevas y alentar el surgimiento de nuevos lugares turísticos. La explicación de la veloz difusión del automóvil en Argentina es múltiple. Debe buscarse en los cambios en las pautas de consumo, que como plantea Fernando Rocchi (1999) se modernizaron a partir del Centenario, y en una sociedad relativamente móvil y abierta, culturalmente favorable a la modernización tecnológica. Debe buscarse, también en las transformaciones en las formas de comercialización de los automóviles y en sus cambios técnicos, que los volvieron más seguros, más confortables, versátiles y baratos. Estos cambios estuvieron asociados al avance de la hegemonía norteamericana de la producción y el comercio automotor (García Heras, 1985).

El viaje de largo aliento en automóvil fue en sus comienzos un asunto de pioneros, en general miembros de la élite. La novedad de los años de 1930 y 1940 fue que, en el marco de una mayor integración material del territorio nacional a partir sobre todo la obra vial, el imperativo de conocer la Patria profunda comenzó a dirigirse a los sectores medios y se amalgamó con el proceso de mercantilización de los lugares 
turísticos, contribuyendo a la vez a la integración simbólica del territorio y al refuerzo de la identidad nacional.

Como ha sostenido Ellen Furlough (1998, p. 248), la clave del atractivo del turismo de masas es su capacidad de resultar accesible y de expresar a la vez distinción social y diferencia cultural. Por supuesto no se trataba en este período de un turismo plenamente masivo, pero sí de un turismo ya de gran escala, que había iniciado un proceso de democratización social que lo había hecho patrimonio de los sectores medios (que en Argentina no eran nada desdeñables en cuanto a su peso demográfico). El caso argentino muestra esta duplicidad que sugiere Furlough de una práctica previsible y prefigurada, domesticada y segura, pero también distinguida (porque no cualquiera podía acceder a un automóvil o disponer de tiempo y recursos para viajar) y distanciada de los otros sociales, que se vuelven, desde la burbuja del auto, parte de paisaje.

El turismo en automóvil en los años de 1930 y 1940, sirvió entonces a la vez para como vector de la apropiación de los paisajes nacionales clave en el fortalecimiento de la identidad nacional y para reforzar jerarquías sociales y culturales entre automovilistas-turistas urbanos y provincianos "auténticos" y "pintorescos", y entre turistas-automovilistas y sectores populares. En la búsqueda de distinción, estos turistas construyeron prácticas recreativas novedosas respecto del turismo de élite que supuestamente imitaban, impulsaron el surgimiento de nuevos lugares turísticos, el consumo de un hotelería diferente y la construcción de segundas residencias y alimentaron un mercado muy amplio de accesorios e implementos para la práctica de los "deportes del turismo".

Sin embargo, en los bordes de la mercantilización de estas prácticas turísticas, y a diferencia del caso europeo, todavía quedó lugar en la Argentina de los 1930 y 1940 para una experiencia que se alineaba con la de los pioneros de las primeras décadas de la automovilidad en Argentina. La Patagonia y la Mesopotamia (como hoy algunos tramos de la ruta 40) continuaron siendo por muchos años territorio de viajeros aventureros y no de turistas.

\section{Referencias Bibliográficas}

AcA. (1940a), Carta de turismo Mar del Plata. Buenos Aires, ACA.

ACA. (1940b), Memoria del Automóvil Club Argentino. Buenos Aires.

ACA. (1942), Zona centro. Buenos Aires, ACA.

Ballent, Anahí. (2003), "Monumentos, turismo e historia: imágenes del noroeste en la arquitectura promovida por el estado, 1935-1945”. Jornadas Perspectivas Históricas sobre el Estado Argentino, Bernal, Universidad Nacional de Quilmes. 
Ballent, Anahí. (2005), "Kilómetro cero: la construcción del universo simbólico del camino en la Argentina de los años treinta”. Boletín del Instituto de Historia Argentina y Americana "Dr. Emilio Ravignani", 27: 107-137.

Ballent, Anahí \& Gorelik, Adrián. (2002), “País urbano o país rural: la modernización territorial y su crisis". In: CATARUzzA, Alejandro (org.). Nueva historia argentina. Tomo VII: Los años treinta. Buenos Aires, Sudamericana, pp. 143-200.

Bertoncello, Rodolfo. (1993), “Configuración socio-espacial de los balnearios del Partido de la Costa (Provincia de Buenos Aires)”. Territorios, 5: 1-95.

Bоотн, Rodrigo et al. (2002), "La suburbanización de Valparaíso y el origen de Viña del Mar: entre la villa balnearia y el suburbio del ferrocarril (1870-1910)”. In: PAsTORIzA, Elisa (org.). Las puertas al mar: consumo, ocio y política en Mar del Plata, Montevideo y Viña del Mar. Buenos Aires, Biblos, pp. 33-49.

Cancela, Arturo. (1933), “Definición del turismo y del turista”. El Hogar, 30 nov., p. 13.

Cresswell, T. (2006), On the move: mobility in the modern Western world. Nueva York, Routledge.

De Grazia, Victoria. (2009), Irresistible empire: America's advance through twentieth-century Europe. Boston, Harvard University Press.

Dirección de Parques Nacionales. (1938), Memoria de la Dirección de Parques Nacionales. Buenos Aires, Dirección de Parques Nacionales.

Dirección Nacional de Vialidad. (1940) Memoria de la Dirección Nacional de Vialidad. Buenos Aires, Dirección Nacional de Vialidad.

Dirección Nacional de Vialidad. (1942) Memoria de la Dirección Nacional de Vialidad, Dirección Nacional de Vialidad.

Elflein, Ada. (1917), Paisajes cordilleranos: descripción de un viajepor los lagos andinos. Buenos Aires, La Prensa.

EL HOGAR. (1931), 30 oct.

"EL WEEK-END, propulsor del turismo" (1941), Automobilismo, nov.

"Estadística mundial de automóviles". (1923), Revista del TCA.

"Estadística mundial de automóviles". (1927), Revista del TCA.

Featherstone, Mike et al. (2005), Automobilities. Londres, Sage.

Ficek, Rosa. (2015), “Motoristas nortamericanos en la Carretera Panamericana: automovilidad y encuentros culturales". Iv Congreso Internacional de Ciencias, Tecnología y Cultura, Santiago, 9 oct.

Furlough, Ellen. (1998), "Making mass vacations: tourism and consumer culture in France, 1930s to 1970". Comparative Studies in Society and History, 40 (2): 247-286.

García Heras, Raúl. (1985), Automotores norteamericanos, caminos y modernización urbana en la Argentina, 1918-1939. Buenos Aires, Libros de Hispanoamérica.

GiUcci, Guillermo. (2007), La vida cultural del automóvil: rutas de la modernidad cinética. Bernal, Universidad Nacional de Quilmes/Prometeo 3010. 
Harp, Stephen L. (2002), "The Michelin red guides: social differentiation in early-twentieth-century French tourism”. In: Koshar, Rudy (org.). Histories of leisure. Nueva York/Oxford, Berg, pp. 191-214.

“LA AMÉriCA Latina construye carreteras para 177.000 automóviles nuevos”. (1927), Caminos y Turismo, 46.

Liernur, Francisco. (1999), "Casas y jardines: la construcción del dispositivo doméstico argentino, 1870-1930”. In: Devoto, Fernando \& Madero, Marta (orgs.). Historia de la vida privada en Argentina. Buenos Aires, Taurus, tomo 2, pp. 99-138.

Lois, Carla \& Troncoso, Claudia. (2004), "Políticas turísticas y peronismo: los atractivos turísticos promocionados en Visión de Argentina (1950)”. Pasos, 2 (2): 281-294.

Margalit, Harry. (2016), Energy, cities and sustainability: an historical approach. Londres, Routledge.

McShane, Clay. (1995), Down the asphalt path: the automobile and the American city. Nueva York, Columbia University Press.

Mom, Gijs. (2011), “Encapsulating culture: European car travel, 1900-1940”.Journal of Tourism History, 3 (3): 289-307.

Pastoriza, Elisa. (2011), La conquista de las vacaciones. Buenos Aires, Edhasa.

Pastoriza, Elisa \& Zuppa, Graciela. (2004), “La conquista de las riberas: política, cultura, turismo y democratización social. Mar del Plata (1886-1970)”. Trace, 45: 93-109.

Piglia, Melina. (2008), "Ciudades de lona: el ACA y la construcción de los campings como lugares turísticos en la entreguerra (1926-1940)”. In: Lois, Carla \& Zusman, Perla (orgs.). Viajes y geografias: turismo, migraciones y exploraciones en la construcción de lugares. Buenos Aires, Prometeo.

Piglia, Melina. (2013), "El ACA e YpF entre las administraciones conservadoras y el peronismo: la red nacional de estaciones de servicio". Boletín del Instituto de Historia Argentina y Americana "Dr. Emilio Ravignani", 37: 143-173.

Piglia, Melina. (2014), Autos, rutas y turismo: el Automóvil Club y el Estado. Buenos Aires, Siglo XXI.

PIRIE, Gordon. (2009), "Incidental tourism: British Imperial air travel in the 1930s". Journal of Tourism History, 1 (1): 46-66.

REVISTA ACA. (1928), mar., s/n.

Rocchi, F. (1999), “Inventando la soberanía del consumidor: publicidad, privacidad y revolución del mercado en la Argentina (1860-1940)". In: Devoto, Fernando \& Madero, Marta (orgs). Historia de la vida privada en Argentina. Buenos Aires, Taurus, tomo 2, pp. 301-322.

SARLO, Beatriz. (1992), La imaginación técnica: sueños modernos de la cultura argentina. Buenos Aires, Nueva Visión.

URRY, John. (2000), Sociology beyond societies: mobility for the twentieth-first century. Londres/ Nueva York, Routledge. 
URRY, John. (2002), The tourist gaze. Londres, Sage.

ZILCOSKy, John. (2008), Writing travel: the poetics and politics of the modern journey. Toronto, University of Toronto Press.

\section{Resumen}

Turismo en automóvil en Argentina (1920-1950)

La Argentina llegó a ser en la entreguerra, el país latinoamericano con más automóviles. El viaje por placer en automóvil tuvo un papel protagónico en la temprana automovilidad, pero sus características se transformaron a partir de fines de los años de 1920 y comienzos de los de 1930, cuando fue adoptado por los sectores medios y se volvió una actividad más previsible y mercantilizada. La difusión del automovilismo en la Argentina fue un proceso casi simultáneo con el desarrollo de lo "turismo nacional". El viaje de largo aliento en automóvil fue en sus comienzos un asunto de pioneros, en general miembros de la élite. La novedad de los años de 1930 y 1940 fue que, en el marco de una mayor integración material del territorio nacional a partir sobre todo la obra vial, el imperativo de conocer la Patria profunda comenzó a dirigirse a los sectores medios y se amalgamó con el proceso de mercantilización de los lugares turísticos. El turismo en automóvil en los años de 1930 y 1940, sirvió a la vez para como vector de la apropiación de los paisajes nacionales clave en el fortalecimiento de la identidad nacional y para reforzar jerarquías sociales y culturales.

Palabras-clave: Automovilidad; Sectores medios; Turismo en automóvil.

\section{Resumo}

O turismo de automóvel na Argentina (1920-1950)

Entre as duas guerras mundiais, a Argentina se tornou o país latino-americano com o maior número de automóveis. A viagem de carro a lazer desempenhou um papel fundamental no início da automobilidade, mas suas características foram transformadas no final dos anos de 1920 e início dos de 1930, quando foi adotada pelos setores médios e se tornou uma atividade mais previsível e mercantilizada. A difusão do automóvel na Argentina foi um processo quase simultâneo com o desenvolvimento do "turismo nacional". As viagens longas de automóvel foram, no início, uma atividade de pioneiros, em geral membros da elite. A novidade nos anos de 1930 e 1940 foi que o imperativo de conhecer a pátria profunda se dirigiu a setores médios e se amalgamou com o processo de mercantilização dos lugares turísticos. O turismo de automóvel, nos anos de 1930 e 1940, serviu tanto como vetor da apropriação das paisagens nacionais, processo chave no fortalecimento da identidade nacional, como para reforçar hierarquias sociais e culturais. Palavras-chave: Automobilidade; Setores médios; Turismo rodoviário. 


\section{Abstract}

\section{Automobile tourism in Argentina (1920-1950)}

Between the two World Wars Argentina became the Latin American country with the largest number of automobiles. The pleasure trip by car played a leading role in the early auto-mobility, but its characteristics were transformed from the late 1920s and early 1930s, when it was adopted by the middle sectors and became a more predictable and commercialized activity. The spread of motoring in Argentina was almost simultaneous with the development of "national tourism". The long-term automobile journey was in the beginning a matter of pioneers, generally members of the elite. The novelty of the 1930s and 1940s was that the imperative of knowing the deep Homeland was addressed to the middle sectors and merged with the process of commodification of tourist places. Automobile tourism served both as a vector for the appropriation of key national landscapes, and thus the strengthening of national identity, and as means of reinforcing social and cultural hierarchies.

Keywords: Auto-mobility; Middle sectors; Tourism automobile.

Texto recebido em 28/12/2017 e aprovado em 11/1/2018.

DOI: $10.11606 / 0103-2070 . t s .2018 .142085$

MELINA PIGLIA é professora e pesquisadora assistente do Consejo Nacional de Investigaciones Científicas y Técnicas (Conicet), Centro de Estudos Históricos, Universidade Nacional de Mar del Plata (Argentina).E-mail: pigliamelina@gmail.com. 